\title{
Suplementação alimentar de ovelhas no terço final da gestação: desempenho de ovelhas e cordeiros até o desmame ${ }^{1}$
}

\section{Feed supplementation during the last third of gestation: effects on ewes and lambs up to weaning}

\author{
José Moura Filho²; Edson Luis de Azambuja Ribeiro ${ }^{3 *}$; \\ Leandro das Dores Ferreira da Silva²; Marco Antonio da Rocha²; \\ Ivone Yurika Mizubuti ${ }^{3}$; Elzânia Sales Pereira ${ }^{4}$; Rinaldo Masato Mori ${ }^{5}$
}

\section{Resumo}

\begin{abstract}
Analisou-se o efeito da suplementação alimentar concentrada no terço final de gestação sobre o desempenho das ovelhas e de seus cordeiros até o desmame. Foram utilizadas 53 ovelhas adultas das raças Hampshire Down e Ile de France, com suas proles, separadas em dois grupos: T1 (sem suplementação) e T2 (suplementadas com 250 gramas de uma mistura contendo $75 \%$ de milho triturado e $25 \%$ de farelo de soja). Os animais dos dois tratamentos foram mantidos em pasto de Coastcross e receberam diariamente $2 \mathrm{~kg}$ de silagem de sorgo. Os dados observados foram: pesos das ovelhas ao início da monta e da suplementação e ao parto, e peso ao nascimento e a cada 14 dias até o desmame dos cordeiros, realizado com 70 dias de idade. A suplementação não resultou em maiores pesos ao parto, porém verificou-se que as ovelhas suplementadas apresentaram melhores escores corporais. Todas as ovelhas perderam peso no terço final de gestação, porém, as ovelhas que receberam suplementação apresentaram perdas menores. A suplementação das ovelhas influenciou somente no peso dos cordeiros ao nascimento, não ocorrendo influência nos outros pesos e ganhos de peso e mortalidade dos cordeiros até o desmame. Ovelhas de seis dentes foram mais pesadas que ovelhas de quatro e oito dentes durante todo o período experimental. Ovelhas de oito dentes apresentaram maior taxa de partos gemelares e seus cordeiros apresentaram maior taxa de mortalidade do que aqueles provenientes de ovelhas de seis dentes. Não houve diferença no desempenho entre cordeiros dos dois grupamentos genéticos. Concluise que a suplementação com concentrados possibilitou uma melhor condição da ovelha ao parto, porém não afetou os parâmetros produtivos dos cordeiros até o desmame.
\end{abstract}

Palavras-chave: Condição corporal, mortalidade, ovino, parto, peso, reprodução

1 Apoio Financeiro: CNPq.

2 Professores do Departamento de Zootecnia da Universidade Estadual de Londrina- PR.

3 Professores do Departamento de Zootecnia da UEL. Pesquisadores CNPq. * Autor para correspondência.

4 Professora do Departamento de Zootecnia da UNIOESTE, Marechal Cândido Rondon - PR.

5 Aluno do Programa de Pós-Graduação em Ciência Animal da UEL.

* Autor para correspondência. 


\begin{abstract}
The objective of this work was to verify the effects of feed supplementation with concentrate during the last third of gestation on ewes and lambs explored for meat production up to weaning. Fifty-three adult Hampshire and Ile de France ewes with their lambs were used in this experiment. Ewes were divided in two groups: T1 (without supplementation) and T2 (supplemented with $250 \mathrm{~g}$ of a mixture of $75 \%$ of grounded corn and $25 \%$ of soybean meal). Animals were maintained on Coastcross pasture and received $2.0 \mathrm{~kg}$ of sorghum silage every day. The collected data from ewes were: Weights at beginning of the breeding season, at the beginning of supplementation and at lambing; from lambs it was collected weights at birth and at every 14 days up to weaning. Supplemented ewes presented greater body condition scores at lambing than non-supplemented ewes, however supplementation did not affect body weight at lambing. Furthermore, supplemented ewes had smaller weight losses during the last third of gestation. Supplementation of ewes affected the birth weight of lambs, but did not influence the other weights, weight gains and mortality of lambs up to weaning. Six teeth ewes were heavier than four and eight teeth ewes during the whole experimental period. Eight teeth ewes presented greater twin lambing rates and a greater mortality of lambs than six teeth ewes. There were no differences in the performance of the lambs of the two genetic groups. It was concluded that the feed supplementation allowed a better body condition to ewes at lambing, however, it did not affect the lamb production up to weaning.
\end{abstract}

Key words: Body condition, lambing, mortality, reproduction, sheep, weight

\section{Introdução}

O Brasil apresenta grande potencial para a criação de ovinos de corte, porém, o maior empecilho para o crescimento desta atividade se refere a baixa eficiência dos rebanhos. Para a melhoria do desempenho reprodutivo, deve-se ter um cuidado especial com as ovelhas em gestação. Na ovelha gestante, distinguem-se dois períodos em que as necessidades nutritivas são diferentes. Durante os dois primeiros terços da gestação (90 a 100 dias), ocorre o processo de diferenciação dos órgãos do cordeiro. No terço final, o feto aumenta $70 \%$ do seu tamanho (SIQUEIRA, 1990).

Segundo Minola e Goyenechea (1975), da fecundação até 45 dias antes do parto é o período de menores requerimentos da gestação. Uma alimentação energética excessiva durante este período tem muito pouco efeito sobre o peso do cordeiro ao nascimento, podendo, por outro lado, causar problemas de parição pela excessiva deposição de gordura da ovelha. Por outro lado, a deficiência alimentar nas últimas cinco a seis semanas de gestação pode originar altos percentuais de lãs com feltragem intensa, transtornos metabólicos que podem levar a ovelha à morte, efeitos irreversíveis no potencial de produção do cordeiro, alta taxa de mortalidade de cordeiros, baixa produção de leite nas ovelhas e conseqüente diminuição do ritmo de crescimento do cordeiro (SIQUEIRA, 1990). Além disso, Minola e Goyenechea (1975) citaram que pode ocorrer diminuição do período de gestação entre cinco a seis dias, com conseqüente diminuição de peso ao parto e no crescimento do cordeiro, pode afetar o instinto materno, determinando o abandono da cria, e ainda determinar a falta de sincronização entre o parto e o começo da lactação.

Ribeiro (2001), em sua revisão de literatura sobre perdas reprodutivas em ovinos, citou que a mortalidade de cordeiros em rebanhos comerciais do Rio Grande do Sul se situa na faixa de $30 \%$, e que o baixo peso ao nascimento estaria relacionado com a alta taxa de mortalidade. El-Hag, Fadlalla, e Elmadih (1998) verificaram que a suplementação alimentar pré-acasalamento e durante os últimos 45 dias de gestação resultou em maiores pesos dos cordeiros ao nascimento e menor taxa de mortalidade até o desmame.

Além dos maiores requerimentos nutricionais, deve-se considerar dois aspectos que tendem a agravar a situação das ovelhas ao final da prenhez: 
primeiro, o aproveitamento da energia dos alimentos é muito reduzido (cerca de 5 a $22 \%$, comparando com valores de 40 a $60 \%$ para uma ovelha não gestante) decorrente do fato dos tecidos serem altamente especializados e, segundo, há uma perda do apetite das ovelhas pela redução do volume do trato gastrointestinal, devido a um maior espaço ocupado pelo feto e anexos. O aumento do nível de estrógenos circulantes, produzidos durante a gestação, também contribui para inibir o apetite das ovelhas (SELAIVE-VILLARROEL, 1989).

Pelo fato das raças ovinas de corte utilizadas no Sul do Brasil serem poliéstricas estacionais, onde a época de maior fecundidade ocorre no outono, o período crítico de final de gestação ocorre no inverno. Segundo Figueiró (1989) e Coimbra Filho (1997), nessa época ocorre uma estacionalidade do crescimento nas forrageiras tropicais, havendo déficit de qualidade e quantidade. Desta maneira, ocorre uma baixa digestibilidade das forrageiras, diminuindo a taxa de passagem através do trato digestivo (COOPER; THOMAS, 1989). Sheehan, Lawlor e Bath (1979) afirmaram que o fornecimento de silagem de milho associado à pastagem não possibilita à ovelha gestante de gêmeos atingir os seus requerimentos energéticos. Daí a necessidade de se fornecer uma alimentação com maior densidade energética.

Os objetivos deste trabalho foram verificar os efeitos da suplementação alimentar em ovelhas das raças Ile de France e Hampshire Down, durante o terço final de gestação, criadas a pasto, sobre os pesos das ovelhas e desempenho dos cordeiros até o desmame.

\section{Material e Métodos}

O experimento foi conduzido na Fazenda Escola da Universidade Estadual de Londrina, Londrina, Paraná (Latitude 2320'10" S e Longitude 5109'15" W). O município apresenta altitude média de 610 metros, temperatura ambiental média anual de $20,6^{\circ} \mathrm{C}$, precipitação média anual de $1.439,8 \mathrm{~mm}$, sendo máximo em janeiro (201,4 mm em média) e mínimo em junho (56,5 mm em média) (MAACK, 1981).

Foram utilizadas 53 ovelhas gestantes, de quatro a oito dentes, das raças Ile de France (14 animais) e Hampshire Down (39 animais). As ovelhas foram distribuídas ao acaso, segundo o padrão racial, idade, peso e escore corporal em dois tratamentos: T1-sem fornecimento de suplementação concentrada durante o período de gestação; e T2 - suplementação concentrada no terço final de gestação.

A estação de monta iniciou em 11 de março e se estendeu até 27 de abril de 2003, totalizando um período de 48 dias. A identificação das ovelhas cobertas foi feita pela técnica de tinta na região esterno-ventral do carneiro e inspeção diária do rebanho. Os nascimentos dos cordeiros ocorreram durante o mês de agosto de 2003. Os cordeiros permaneceram juntos com as ovelhas até o desmame (70 dias).

As ovelhas foram mantidas em pastagem com Coastcross (Cynodon dactylon (L.) Pers), numa área de cinco hectares, sendo esta área dividida em sete piquetes. Durante a noite os animais permaneceram em curral semi-coberto com piso concretado e com acesso a um aprisco suspenso com piso ripado. Forneceu-se suplementação mineral a vontade em cochos nos piquetes. Entre os meses de maio e outubro foi fornecido às ovelhas dos dois tratamentos 2,0 kg/cabeça/dia de silagem de sorgo (Sorgum bicolor (L.) Moench).

A ração concentrada para a suplementação das ovelhas do T2 era constituída de $75 \%$ de milho triturado e $25 \%$ de farelo de soja, sendo utilizado um total de $250 \mathrm{~g} /$ cabeça/dia a partir de 21 de junho de 2003 até o parto. O tempo de suplementação variou de 47 dias para as ovelhas que pariram primeiro até 67 dias para as últimas ovelhas a parirem. Após o parto, as ovelhas dos dois tratamentos (T1 e T2) receberam $150 \mathrm{~g} /$ cabeça/dia desta mesma ração concentrada, até os cordeiros completarem um mês de idade. Tanto a silagem como a ração concentrada era fornecida aos animais às 17:30 horas. 
A profilaxia parasitária gastro-entérica foi realizada pela aplicação de anti-helmínticos nos animais que apresentaram resultados laboratoriais acima de 500 ovos por grama de fezes (OPG), e o controle de clostridioses foi feito pela vacinação das ovelhas 30 dias antes do parto e nos cordeiros antes de completarem três meses de idade.

O escore corporal foi medido, junto com as pesagens no início da monta, início da suplementação e ao parto, de acordo com as recomendações descritas por Susin (1996), com escala de pontuação de 1 a 5, com graduação de meio ponto, sendo o escore 1 atribuído a animais muito magros e 5 para animais muito gordos.
Foram efetuadas análises bromatológicas do pasto, silagem de sorgo e ração concentrada para determinar a composição em matéria seca, proteína bruta, extrato etéreo, fibra em detergente neutro, fibra em detergente ácido e matéria mineral (SILVA; QUEIROZ, 2002). Essas análises foram realizadas no Laboratório de Nutrição Animal da Universidade Estadual de Londrina. Foram colhidas duas amostras mensalmente, de junho a agosto, de cada piquete e feita amostragem composta do pasto para realização da análise bromatológica. As amostras foram cortadas rente ao solo, sendo descartado o material morto. Os resultados da composição química são apresentados na Tabela 1.

Tabela 1 - Composição química dos alimentos utilizados (\% na MS).

\begin{tabular}{lccccccc}
\hline Alimento & MS & PB & EE & FB & FDN & FDA & MM \\
\hline Coast-Cross & 41,54 & 9,96 & 1,85 & 29,55 & 79,86 & 37,71 & 7,95 \\
Silagem de sorgo & 32,08 & 7,31 & 2,16 & 30,85 & 69,52 & 34,64 & 5,49 \\
Milho triturado & 90,11 & 9,01 & 4,36 & 2,06 & - & - & 6,49 \\
Farelo de soja & 90,18 & 46,09 & 0,79 & 6,23 & - & - & 5,38 \\
\hline
\end{tabular}

MS: matéria seca; PB: proteína bruta; EE: extrato etéreo; FB: fibra bruta; FDN: fibra em detergente neutro, FDA: fibra em detergente ácido; MM: Matéria Mineral.

As análises estatísticas foram realizadas utilizando-se o pacote estatístico SAS (1994). Os dados de peso, ganhos de peso e escore corporal das ovelhas foram submetidos a análise de variância, tendo como variáveis independentes os efeitos de tratamento, parto (único ou gemelar), padrão racial e idade das ovelhas. Nas análises dos pesos e ganhos de peso dos cordeiros, além das variáveis citadas, incluiu-se no modelo o efeito de sexo. Para o efeito de idade as diferenças entre médias foram comparadas pelo teste t a 5\% de significância. As taxas de mortalidade dos cordeiros foram comparadas pelo teste do qui-quadrado.

\section{Resultados e Discussão}

Na Tabela 2 são apresentados os pesos das ovelhas durante o período experimental. Observouse que a suplementação alimentar das ovelhas no terço final de gestação não resultou em maior peso ao parto, apesar de haver uma diferença de $3,59 \mathrm{~kg}$, em média, a mais nos animais suplementados.

Tabela 2 - Médias de peso $(\mathrm{kg})$ das ovelhas ao início da estação de monta, ao início da suplementação e ao parto, de acordo com manejos alimentares, tipos de parição, idades e grupos raciais.

\begin{tabular}{lccc}
\hline Efeitos & Início de Monta & $\begin{array}{c}\text { Início de } \\
\text { Suplementação }\end{array}$ & Ao Parto \\
\hline Suplementação & & & \\
$\quad$ Não & $58,027 \pm 2,108$ & $56,533 \pm 2,220$ & $49,189 \pm 2,390$ \\
Sim & $57,772 \pm 2,510$ & $56,433 \pm 2,644$ & $52,776 \pm 2,909$ \\
Pr $>$ F & 0,9203 & 0,9701 & 0,2524 \\
Tipo de parição & & & \\
$\quad$ Parto único & $53,916 \pm 2,041^{\mathrm{b}}$ & $53,094 \pm 2,150^{\mathrm{b}}$ & $48,117 \pm 2,290$ \\
$\quad$ Parto gemelar & $63,539 \pm 2,831^{\mathrm{a}}$ & $63,732 \pm 2,982^{\mathrm{a}}$ & $53,847 \pm 3,109$ \\
Pr $>$ F & 0,0104 & 0,0046 & 0,0922 \\
Idade & & & \\
4 dentes & $51,539 \pm 2,099^{\mathrm{b}}$ & $49,310 \pm 2,211^{\mathrm{b}}$ & $45,122 \pm 2,691^{\mathrm{b}}$ \\
6 dentes & $66,458 \pm 4,476^{\mathrm{a}}$ & $66,512 \pm 4,715^{\mathrm{a}}$ & $59,414 \pm 4,871^{\mathrm{a}}$ \\
8 dentes & $55,701 \pm 1,893^{\mathrm{b}}$ & $53,629 \pm 1,994^{\mathrm{b}}$ & $48,411 \pm 2,128^{\mathrm{b}}$ \\
Pr $>\mathrm{F}$ & 0,0094 & 0,0044 & 0,0366 \\
Grupo racial & & & \\
$\quad$ Hampshire Down & $61,212 \pm 1,864^{\mathrm{a}}$ & $59,223 \pm 1,963$ & $53,581 \pm 2,023$ \\
Ile de France & $54,586 \pm 2,812^{\mathrm{b}}$ & $53,743 \pm 2,963$ & $48,383 \pm 3,314$ \\
Pr $>$ F & 0,0209 & 0,0668 & 0,1309 \\
\hline
\end{tabular}

a, b: Médias seguidas de letras diferentes, em colunas, diferem significativamente $(\mathrm{P}<0,05)$ para o mesmo efeito. 
Ao início da estação de monta e início da suplementação alimentar as ovelhas de parto gemelar apresentaram maiores pesos do que aquelas de parto único. Ao parto, não houve diferença significativa no peso entre ovelhas de partos únicos e gemelares.

Em relação a idade das ovelhas, verificou-se que as ovelhas de seis dentes foram mais pesadas $(\mathrm{P}<0,05)$ do que aquelas de quatro e oito dentes. Isso provavelmente ocorreu porque o grupo de ovelhas de oito dentes foi constituído em parte por ovelhas com mais de sete anos.

As ovelhas Hampshire Down foram mais pesadas do que as Ile de France somente ao início da estação de monta. Os pesos das ovelhas dessas duas raças estão de acordo com os pesos citados por Ribeiro et al. (2002), mas estão abaixo dos recomendados para animais puros e bem alimentados (SILVA SOBRINHO, 2001).

Um fato marcante observado nos pesos dos animais, foi a diminuição dos mesmos do início da monta até o parto, independentemente dos animais serem suplementados ou não. Este fato demonstra que apesar da qualidade da forragem não ser ruim (Tabela 1), provavelmente a quantidade disponível estava aquém do necessário para suprir as exigências dos animais.

Na Tabela 3 podem ser observados os ganhos de peso das ovelhas durante o período experimental. Ovelhas suplementadas apresentaram menores perdas de peso do início da suplementação ao parto do que aquelas não suplementadas. Ovelhas que pariram gêmeos perderam mais peso do que aquelas que tiveram partos únicos nos períodos de início da suplementação ao parto e de início da estação de monta até o parto, demonstrando que ovelhas que pariram gêmeos tiveram um maior requerimento nutricional durante a gestação. Em relação à idade $\mathrm{e}$ ao grupo racial, não se verificou diferenças nas variações de peso das ovelhas.

Tabela 3 - Ganhos médios de peso $(\mathrm{kg})$ das ovelhas do início da estação de monta ao início da suplementação (GMIMIS), do início da suplementação ao parto (GMISP) e do início da monta ao parto (GMIMP) de acordo com manejos alimentares, tipos de parição, idades e grupos raciais.

\begin{tabular}{lccc}
\hline Efeitos & GMIMIS & GMISP & GMIMP \\
\hline Suplementação & & & \\
Não & $-1,493 \pm 0,859$ & $-8,695 \pm 1,045^{\mathrm{a}}$ & $-9,290 \pm 1,051$ \\
Sim & $-1,339 \pm 1,023$ & $-5,835 \pm 1,272^{\mathrm{b}}$ & $-6,548 \pm 1,279$ \\
Pr $>\mathrm{F}$ & 0,8818 & 0,0408 & 0,0506 \\
Tipo de parição & & & \\
$\quad$ Parto único & $-0,822 \pm 0,832$ & $-5,032 \pm 1,002^{\mathrm{b}}$ & $-6,268 \pm 1,007^{\mathrm{b}}$ \\
$\quad$ Parto gemelar & $0,193 \pm 1,154$ & $-9,497 \pm 1,360^{\mathrm{a}}$ & $-9,570 \pm 1,367^{\mathrm{a}}$ \\
Pr $>\mathrm{F}$ & 0,0545 & 0,0039 & 0,0294 \\
Idade & & & \\
$\quad$ 4 dentes & $-2,229 \pm 0,856$ & $-5,189 \pm 1,177$ & $-6,408 \pm 1,183$ \\
6 dentes & $0,053 \pm 1,825$ & $-9,127 \pm 2,131$ & $-8,621 \pm 2,142$ \\
8 dentes & $-2,072 \pm 0,772$ & $-7,479 \pm 0,931$ & $-8,728 \pm 0,936$ \\
Pr $>\mathrm{F}$ & 0,4813 & 0,1553 & 0,2677 \\
Grupo racial & & & \\
Hampshire Down & $-1,989 \pm 0,760$ & $-7,588 \pm 0,885$ & $-8,258 \pm 0,890$ \\
Ile de France & $-0,843 \pm 1,147$ & $-6,942 \pm 1,449$ & $-7,580 \pm 1,457$ \\
Pr $>\mathrm{F}$ & 0,3155 & 0,6636 & 0,6498 \\
\hline
\end{tabular}

a,b: Médias seguidas de letras diferentes, em colunas, diferem significativamente $(\mathrm{P}<0,05)$ para o mesmo efeito.

Médias para escores corporais das ovelhas durante o período experimental são apresentadas na Tabela 4. Apesar das ovelhas suplementadas não terem apresentado maiores pesos ao parto, verificouse que esses animais apresentaram maiores escores corporais. As ovelhas que pariram gêmeos tiveram maiores médias de escore corporal ao início da suplementação e ao parto. No início da monta, apesar do escore de condição corporal ser 15\% maior para as ovelhas com gêmeos do que para as com cordeiros únicos, esta diferença não foi estatisticamente significativa $(\mathrm{P}>0,18)$. De qualquer maneira, estes dados revelam que para a obtenção de partos gemelares há a necessidade das ovelhas terem melhor condição corporal (MINOLA; GOYENECHEA, 1975). 
Tabela 4 - Médias de escores corporais das ovelhas ao início da estação de monta, ao início da suplementação e ao parto de acordo com manejos alimentares, tipos de parição, idades e grupos raciais.

\begin{tabular}{lccc}
\hline Efeitos & Início de Monta & $\begin{array}{c}\text { Início de } \\
\text { Suplementação }\end{array}$ & Parto \\
\hline Suplementação & $2,960 \pm 0,156$ & $2,907 \pm 0,140$ & $2,260 \pm 0,115^{\mathrm{b}}$ \\
$\quad$ Não & $2,951 \pm 0,185$ & $2,903 \pm 0,167$ & $2,785 \pm 0,140^{\mathrm{a}}$ \\
Sim & 0,9609 & 0,9812 & 0,0011 \\
Pr $>$ F & & & \\
Tipo de parição & $2,773 \pm 0,151$ & $2,744 \pm 0,136^{\mathrm{b}}$ & $2,338 \pm 0,110^{\mathrm{b}}$ \\
$\quad$ Parto único & $3,190 \pm 0,209$ & $3,285 \pm 0,189^{\mathrm{a}}$ & $2,708 \pm 0,150^{\mathrm{a}}$ \\
$\quad$ Parto gemelar & 0,1867 & 0,0234 & 0,0262 \\
Pr $>$ F & & & \\
Idade & $2,782 \pm 0,155$ & $2,747 \pm 0,140$ & $2,387 \pm 0,130^{\mathrm{ab}}$ \\
$\quad$ 4 dentes & $3,351 \pm 0,331$ & $3,311 \pm 0,298$ & $2,901 \pm 0,235^{\mathrm{a}}$ \\
6 dentes & $2,733 \pm 0,140$ & $2,655 \pm 0,126$ & $2,279 \pm 0,103^{\mathrm{b}}$ \\
$\quad$ dentes & 0,1945 & 0,1099 & 0,0479 \\
Pr $>$ F & & & \\
Grupo racial & $2,999 \pm 0,138$ & $2,944 \pm 0,124$ & $2,595 \pm 0,098$ \\
Hampshire Down & $2,912 \pm 0,208$ & $2,865 \pm 0,187$ & $2,450 \pm 0,160$ \\
Ile de France & 0,6748 & 0,6699 & 0,3786 \\
Pr $>$ F & & & \\
\hline
\end{tabular}

a, b: Médias seguidas de letras diferentes, em colunas, diferem significativamente $(\mathrm{P}<0,05)$ para o mesmo efeito.

Apesar das ovelhas de seis dentes terem apresentado maiores pesos que as de quatro e oito dentes, observou-se maiores médias de escore corporal somente ao parto em relação às ovelhas de oito dentes, não havendo diferença com ovelhas de quatro dentes. Apesar da diferença de peso ao início da estação de monta entre os dois grupos genéticos, não houve diferença em relação aos escores corporais. Caldeira e Vaz Portugal (1998) citaram que a mensuração do escore corporal é um método mais eficaz do que o peso corporal quando se compara animais de diferentes raças ou cruzamentos.
Em relação aos escores de condição corporal, Susin (1996) citou que antes da monta as ovelhas devem estar com uma condição entre 2,5 a 3,0 e que ao parto esta condição deve ser de 3,0 a 3,5. Ribeiro et al. (2003) observaram, em um rebanho de ovelhas Corriedale, uma associação positiva entre prenhez e condição corporal. Como observado na Tabela 4, os escores no início da monta estavam de acordo com o recomendado, porém, ao parto estavam abaixo do esperado.

$\mathrm{Na}$ Tabela 5 são apresentadas as médias para os pesos dos cordeiros, onde observou-se que a suplementação alimentar das ovelhas durante o terço final de gestação resultou em um peso dos cordeiros ao nascimento $10 \%$ maior do que o peso dos cordeiros de ovelhas não suplementadas, apesar desta diferença não ser significativa $(\mathrm{P}>0,08)$. Esta pequena diferença é sem dúvida o resultado dos pesos e escores de condição corporal das mães. Minola e Goyenechea (1975) observaram pesos ao nascimento significativamente menores para cordeiros onde as mães perderam em média $1,0 \mathrm{~kg}$ por semana, comparados com aqueles onde as mães ganharam $1,0 \mathrm{~kg}$ por semana, nas últimas cinco semanas de gestação $(3,65$ vs $4,15 \mathrm{~kg})$. Nas pesagens subseqüentes, a diferença observada ao nascimento em favor dos cordeiros filhos de ovelhas suplementadas desapareceu, não sendo verificadas diferenças entre os pesos.

Tabela 5 - Médias de pesos $(\mathrm{kg})$ de cordeiros do nascimento ao desmame (70 dias).

\begin{tabular}{|c|c|c|c|c|c|c|}
\hline Efeito & Peso nascimento & Peso 14 dias & Peso 28 dias & Peso 42 dias & Peso 56 dias & Peso 70 dias \\
\hline \multicolumn{7}{|l|}{ Suplementação } \\
\hline Não & $3,611 \pm 0,153$ & $6,140 \pm 0,323$ & $8,548 \pm 0,558$ & $9,979 \pm 0,656$ & $11,579 \pm 0,788$ & $12,455 \pm 0,786$ \\
\hline Sim & $3,974 \pm 0,185$ & $6,142 \pm 0,375$ & $7,832 \pm 0,647$ & $9,221 \pm 0,770$ & $10,267 \pm 0,926$ & $11,513 \pm 0,924$ \\
\hline $\operatorname{Pr}>\mathrm{F}$ & 0,0839 & 0,9970 & 0,3625 & 0,4186 & 0,2496 & 0,4054 \\
\hline \multicolumn{7}{|l|}{ Tipo de parto } \\
\hline Único & $4,227 \pm 0,160^{\mathrm{a}}$ & $7,040 \pm 0,311^{\mathrm{a}}$ & $9,375 \pm 0,538^{\mathrm{a}}$ & $11,092 \pm 0,633^{\mathrm{a}}$ & $12,910 \pm 0,762^{\mathrm{a}}$ & $13,782 \pm 0,761^{\mathrm{a}}$ \\
\hline Gemelar & $3,358 \pm 0,176^{\mathrm{b}}$ & $5,242 \pm 0,353^{\mathrm{b}}$ & $7,005 \pm 0,611^{\mathrm{b}}$ & $8,109 \pm 0,729^{\mathrm{b}}$ & $8,937 \pm 0,874^{\mathrm{b}}$ & $10,186 \pm 0,873^{\mathrm{b}}$ \\
\hline $\operatorname{Pr}>\mathrm{F}$ & 0,0001 & 0,0001 & 0,0013 & 0,0008 & 0,0003 & 0,0009 \\
\hline \multicolumn{7}{|l|}{ Idade } \\
\hline 4 dentes & $3,321 \pm 0,174^{\mathrm{b}}$ & $5,908 \pm 0,371$ & $8,336 \pm 0,640$ & $9,525 \pm 0,753$ & $10,998 \pm 0,905$ & $12,185 \pm 0,904$ \\
\hline 6 dentes & $4,422 \pm 0,320^{\mathrm{a}}$ & $6,941 \pm 0,625$ & $9,112 \pm 1,080$ & $10,847 \pm 1,270$ & $11,741 \pm 1,518$ & $13,256 \pm 1,515$ \\
\hline 8 dentes & $3,635 \pm 0,136^{\mathrm{b}}$ & $5,573 \pm 0,281$ & $7,121 \pm 0,486$ & $8,429 \pm 0,582$ & $10,030 \pm 0,707$ & $10,511 \pm 0,706$ \\
\hline $\operatorname{Pr}>\mathrm{F}$ & 0,0145 & 0,1089 & 0,0948 & 0,1307 & 0,4374 & 0,1129 \\
\hline \multicolumn{7}{|l|}{ Raça } \\
\hline Hampshire Down & $3,807 \pm 0,126$ & $6,285 \pm 0,245$ & $8,477 \pm 0,424$ & $9,559 \pm 0,505$ & $10,540 \pm 0,605$ & $11,512 \pm 0,604$ \\
\hline Ile de France & $3,778 \pm 0,211$ & $5,996 \pm 0,437$ & $7,902 \pm 0,756$ & $9,642 \pm 0,888$ & $11,306 \pm 1,061$ & $12,456 \pm 1,059$ \\
\hline $\operatorname{Pr}>\mathrm{F}$ & 0,8955 & 0,5380 & 0,4783 & 0,9306 & 0,5027 & 0,4086 \\
\hline \multicolumn{7}{|l|}{ Sexo } \\
\hline Fêmea & $3,642 \pm 0,170$ & $6,144 \pm 0,337$ & $8,099 \pm 0,582$ & $9,344 \pm 0,684$ & $10,451 \pm 0,818$ & $11,646 \pm 0,816$ \\
\hline Macho & $3,943 \pm 0,159$ & $6,138 \pm 0,328$ & $8,281 \pm 0,567$ & $9,856 \pm 0,674$ & $11,395 \pm 0,807$ & $12,322 \pm 0,805$ \\
\hline $\operatorname{Pr}>\mathrm{F}$ & 0,1192 & 0,9890 & 0,7905 & 0,5310 & 0,3367 & 0,4891 \\
\hline
\end{tabular}

a, b: Médias seguidas de letras diferentes, em colunas, para o mesmo efeito, diferem significativamente $(\mathrm{P}<0,05)$. 
Na comparação de pesos entre cordeiros provenientes de partos únicos e duplos, observou-se que os cordeiros provenientes de partos únicos sempre apresentaram pesos maiores do nascimento ao desmame (70 dias). Ribeiro et al. (2002) observaram que cordeiros gêmeos foram $27,3 \%$ mais leves ao nascimento e $51,3 \%$ mais leves ao desmame do que cordeiros únicos.

Em relação às idades das ovelhas, houve diferença somente no peso ao nascimento, onde cordeiros provenientes de ovelhas de seis dentes foram mais pesados do que aqueles oriundos de ovelhas de quatro e oito dentes. Não foram observadas diferenças para os pesos dos cordeiros, do nascimento ao desmame, para grupo racial e sexo. No geral, os pesos ao desmame são próximos aos observados por Ribeiro et al. (2002) e Mexia et al. (2004).

Na Tabela 6 são apresentadas as médias para ganhos de peso dos cordeiros do nascimento ao desmame em pesagens realizadas a cada 14 dias. Verificou-se que a suplementação alimentar das ovelhas durante o terço final de gestação não influenciou os ganhos de peso dos cordeiros. Apesar das ovelhas suplementadas terem apresentado uma melhor condição corporal ao parto do que as não suplementadas, esta condição não pode ser considerada boa (SUSIN, 1996), e isto ocorreu em função da perda de peso das ovelhas. Segundo vários autores (MINOLA; GOYENECHEA, 1975; SUSIN, 1996; SILVA SOBRINHO, 2001), ovelhas com nutrição inadequada no final de gestação produzem pouco leite, o que acarreta em baixos ganhos de peso dos cordeiros.

Os ganhos de peso dos cordeiros oriundos de partos únicos foram maiores do que os dos cordeiros gêmeos do nascimento até 14 dias e dos 28 aos 42 dias de idade, resultando em maior ganho médio de peso desses animais durante o período de amamentação. De acordo com Minola e Goyenechea (1975), apesar de ovelhas com gêmeos produzirem mais leite do que ovelhas com cordeiros únicos, estes últimos ganham individualmente mais peso.

Tabela 6 - Ganhos médios de peso (kg) de cordeiros do nascimento ao desmame (70 dias).

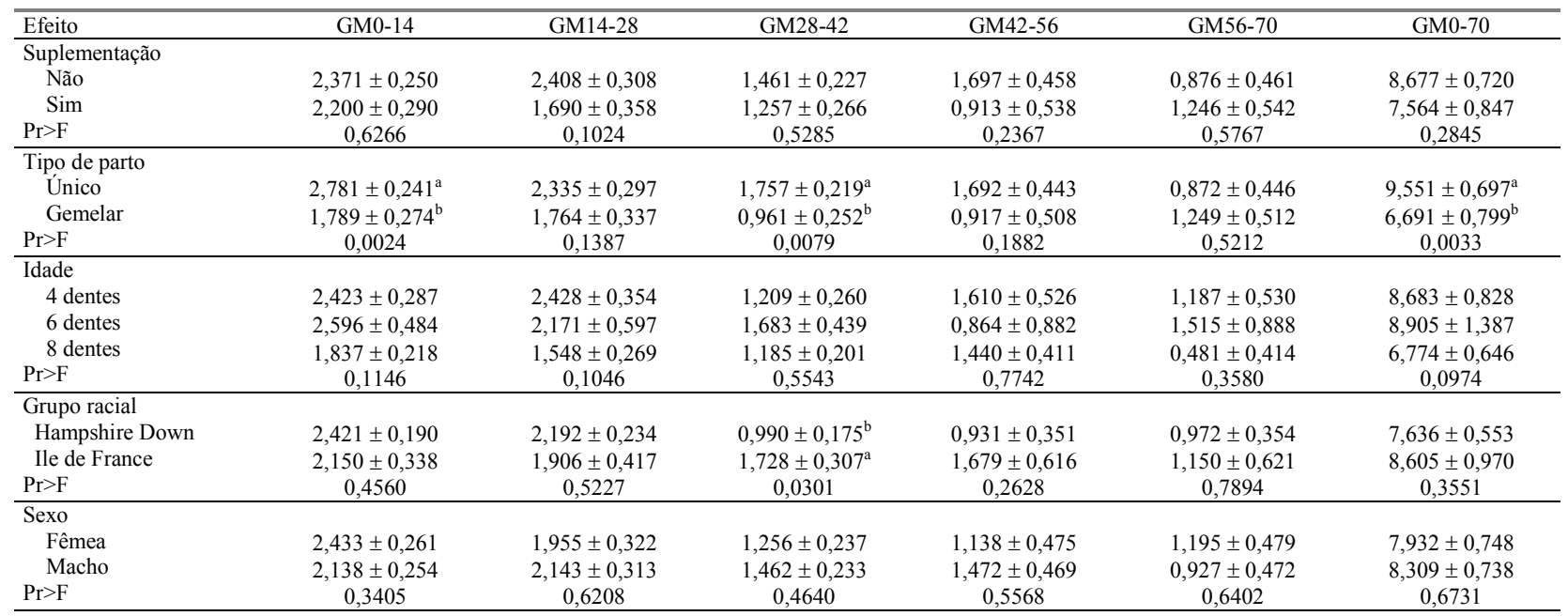

a, b: Médias seguidas de letras diferentes, em colunas, para o mesmo efeito, diferem significativamente $(\mathrm{P}<0,05)$.

Cordeiros filhos de ovelhas de diferentes faixas etárias não diferiram nos ganhos de peso até o desmame. Em relação aos grupos raciais, a única diferença observada foi no período de 28 a 42 dias de idade, onde os cordeiros Hampshire Down ganharam menos peso do que os cordeiros Ile de France, porém, essas diferenças não se refletiram no ganho médio de peso dos cordeiros do nascimento ao desmame. Não se verificou diferenças nos ganhos de peso entre cordeiros machos e fêmeas em nenhum 
dos períodos analisados até o desmame. Esses resultados, estão de acordo com os observados por Ribeiro et al. (2002).

Os dados de mortalidade dos cordeiros são apresentados na Tabela 7, onde pode-se observar que houve diferença somente entre cordeiros filhos de ovelhas de seis e oito dentes, onde os filhos de ovelhas de seis dentes apresentaram mortalidade zero. Deve-se ressaltar o pequeno número de cordeiros provenientes de ovelhas de seis dentes, e isso pode ter exacerbado essa diferença. Além disso, ovelhas de oito dentes foram as que apresentaram maior número de partos gemelares, os quais, apesar de não ser estatisticamente diferentes, apresentaram maior mortalidade.

Ribeiro et al. (2002) observaram mortalidade até o desmame de $43,5 \%$ entre cordeiros gêmeos e de apenas 3,6\% para cordeiros únicos. Os resultados observados, também, estão de acordo com os apresentados por Mexia et al. (2004), sendo que estes autores observaram uma mortalidade média até os 60 dias de idade de 39,0\%. Minola e Goyenechea (1975) consideram como boas as mortalidades de cordeiros de $13 \%$ ou menos, como médias de 13 a $27 \%$, e como ruins acima de $27 \%$.

Tabela 7 - Mortalidade (percentagem entre parênteses) de cordeiros entre o nascimento e o desmame.

\begin{tabular}{lccc}
\hline Efeito & Nascidos & Desmamados & Mortos \\
\hline Suplementação & & & \\
Não & 28 & $20(71.43)$ & $8(28.57)$ \\
Sim & 29 & $24(82.86)$ & $5(17.24)$ \\
\hline Tipo de parto & & & \\
Único & 31 & $26(83.87)$ & $5(16.13)$ \\
Gemelar & 26 & $18(69.23)$ & $8(30.77)$ \\
\hline Idade & & & \\
4 dentes & 19 & $16(84.21)^{\mathrm{ab}}$ & $3(15.79)^{\mathrm{ab}}$ \\
6 dentes & 6 & $6(100)^{\mathrm{b}}$ & $0(0)^{\mathrm{b}}$ \\
8 dentes & 32 & $22(68.75)^{\mathrm{a}}$ & $10(31.25)^{\mathrm{a}}$ \\
\hline Grupo racial & & & \\
Hampshire Down & 42 & $33(78.57)$ & $9(21.43)$ \\
Ile de France & 15 & $11(73.33)$ & $4(26.67)$ \\
\hline Sexo & & & \\
Fêmea & 25 & $20(80)$ & $5(20)$ \\
Macho & 32 & $24(75)$ & $8(25)$ \\
\hline Total & 57 & $44(77,19)$ & $13(22,81)$ \\
\hline
\end{tabular}

a, b: Médias seguidas de letras diferentes, em colunas, para o mesmo efeito, diferem significativamente ao nível de $5 \%$.
Em relação a idade das ovelhas, como citado anteriormente, no grupo de ovelhas com oito dentes, havia animais com sete anos e mais velhas. Roda, Santos e Cunha (1995) observaram que ovelhas com essas idades apresentaram cordeiros mais leves ao nascimento e ao desmame, e com maiores taxas de mortalidade. Os autores sugerem que esses animais devem ser descartados devido ao baixo desempenho reprodutivo.

\section{Conclusões}

A suplementação no terço final de gestação com ração concentrada, na quantia utilizada neste experimento, em ovelhas que continuam perdendo peso não é recomendada, pois não houve melhoria no desempenho dos cordeiros.

Ovelhas e cordeiros dos dois grupamentos genéticos apresentaram desempenho similar.

Ovelhas de oito dentes, velhas, apresentaram desempenho produtivo menor, devendo ser substituídas por ovelhas mais jovens.

\section{Referências}

CALDEIRA, R. M.; VAZ PORTUGAL, A. Condição corporal: conceitos, métodos de avaliação e interesse da sua utilização como indicador na exploração de ovinos. Revista Portuguesa de Ciências Veterinárias, Lisboa, v. 93, n. 526, p. 95-102, 1998.

COIMBRA FILHO, A. Técnicas de criação de Ovinos. 2.ed. Guaíba: Agropecuária, 1997. 102 p.

COOPER, M. McG.; THOMAS, R. J. Profitable Sheep Farming. 5.ed. Ipswich: Farming Press, 1989. 198 p.

EL-HAG, F. M.; FADLALLA, B.; ELMADIH, M. A. Effect of strategic supplementary feeding on ewe productivity under range conditions in North Kordofan, Sudan. Small Ruminant Research, Amsterdam, v. 30, p. 67-71, 1998.

FIGUEIRÓ, P. R. P. Manejo Alimentar do rebanho ovino. In: SIMPÓSIO PAULISTA DE OVINOCULTURA, 1., 1988, Botucatu. Anais... Campinas: Fundação Cargill, 1989. p. 22-33.

MAACK, R. Geografia Física do Estado do Paraná. 2.ed. Rio de Janeiro: José Olympio, 1981. 450 p. 
MEXIA, A. A.; MACEDO, F. D.; ALCALDE, C. R.; SAKAGUTI, E. S.; MARTINS, E. N.; ZUNDT, M.; YAMAMOTO, S. M.; MACEDO, R. M. G. Desempenhos reprodutivo e produtivo de ovelhas Santa Inês suplementadas em diferentes fases da gestação. Revista Brasileira de Zootecnia, Viçosa, v. 33, n. 3, p. 658-667, 2004.

MINOLA, J.; GOYENECHEA J. Praderas \& Lanares: Producion ovina en alto nivel. Montevideo: Hemisferio Sur, $1975.365 \mathrm{p}$.

RODA, D. S.; SANTOS, L. E.; CUNHA, E. A. Peso ao nascer e mortalidade pré-desmame em cordeiros das raças Ideal e Corriedale. Boletim de Industria Animal, Nova Odessa, v. 52, n. 1, p. 67-70, 1995.

RIBEIRO, L. A. O. Perdas reprodutivas e doenças de ovinos. In: SIMPÓSIO PARANAENSE DE OVINOCULTURA. 9., Ponta Grossa, 2001. Anais... Ponta Grossa: UEPG, 2001. p. 59-62.

RIBEIRO, E. L. A.; SILVA, L. D. F.; MIZUBUTI, I. Y.; ROCHA, M. A.; SILVA, A. P.; MORI, R. M.; FERREIRA, D. O. L.; CASIMIRO, T. R.. Desempenho produtivo de ovelhas acasaladas no verão e no outono recebendo ou não suplementação alimentar durante o acasalamento. Semina Ciência Agrária, Londrina, v. 23, p. 35-44, 2002.
RIBEIRO, L. A. O; FONTANA, F. C.; WALD, V. B.; GREGORY, R. M.; MATTOS, R. C. Relação entre a condição corporal e a idade das ovelhas no encarneiramento com a prenhez. Ciência Rural, Santa Maria, v. 33, n. 2, p.357-361, 2003.

SAS INSTITUTE. SAS/STAT User's Guide. Cary, 1994. v. 2.

SELAIVE-VILLARROEL, A. B. Manejo reprodutivo dos ovinos. In: SIMPÓSIO PAULISTA DE OVINOCULTURA, 1., 1988, Botucatu. Anais... Campinas: Fundação Cargill, 1989.p. 67-79.

SHEEHAN, W.; LAWLOR, M. J.; BATH, I. H. Silage intake in relation to the energy requirements of ewes in late pregnancy. Irish Journal of Agricultural Research, Dublin, v. 18, n. 2, p. 97-103, 1979.

SILVA, D. J.; QUEIROZ, A. C. Análise de Alimentos: métodos químicos e biológicos. 3.ed. Viçosa: UFV, 2002. 235 p.

SILVA SOBRINHO, A. G. Criação de ovinos. 2.ed. Jaboticabal: FUNEP, 2001. 302 p.

SIQUEIRA, E. R. Estratégias de alimentação do rebanho e tópicos sobre produção de carne ovina. In: SILVA SOBRINHO, A. G. (Ed.). Produção de Ovinos. Jaboticabal: FUNEP, 1990. p. 157-171.

SUSIN, I. Exigências nutricionais de ovinos e estratégias de alimentação. In: SILVA SOBRINHO, A. G.(ed.) Nutrição de Ovinos. Jaboticabal: FUNEP, 1996. p. 119-141. 